\title{
COMPARISON OF TESTING RESULTS OF DRIVERS ON THE ROAD TRAFFIC SIMULATOR AND ON THE SET OF PSYCHOLOGICAL TESTS
}

\author{
Alexey N. \\ Todorev \\ Department of \\ Descriptive \\ Geometry, \\ Volgograd State \\ Technical \\ University \\ VSTU \\ Volgograd, \\ Russian \\ Federation \\ alexwork@mail.
}

$\mathrm{ru}$
Olga A.

Shabalina

Department of

Computer

Aided Design

Systems,

Volgograd

State Technical

University

VSTU

Volgograd,

Russian

Federation

o.a.shabalina

@ gmail.com

\author{
Maksim N. \\ Dyatlov \\ Department of \\ Descriptive \\ Geometry, \\ Volgograd \\ State \\ Technical \\ University \\ VSTU \\ Volgograd, \\ Russian \\ Federation \\ makdyatlov \\ @yandex.ru
}

\author{
Rodion A. \\ Kudrin \\ Department of \\ Normal \\ Physiology, \\ Volgograd \\ State Medical \\ University \\ VolgSMU \\ Volgograd, \\ Russian \\ Federation \\ rodion.kudrin7 \\ 6@yandex.ru
}

\author{
Yuriy Ya. \\ Komarov \\ Department of \\ Motor Transport, \\ Volgograd State \\ Technical \\ University \\ VSTU \\ Volgograd, \\ Russian Federation \\ atrans@vstu.ru
}

Abstract - In the article, the convolution of the test results of drivers of motor vehicles on the auto-simulator and on the complex of psychological tests "effecton" is considered.

Keywords - professionally important qualities (PIQ), drivers of vehicles, reduction of recorded indicators.

\section{INTRODUCTION}

The study and diagnosis of significant psychophysiological qualities of drivers of motor vehicles make it possible to solve problems related to the human factor more effectively [1].

The authors of the work carried out research of the peculiarities of the professional activity of drivers of motor vehicles and developed a methodology for identifying professionally important qualities (PIQ) using expert assessments $[2,3]$.

\section{GOAL}

As a result of the analysis of existing tests for assessing the degree of development of sensorimotor reactions, the authors developed test tasks for the evaluation of sensorimotor reactions in conditions close to the work of drivers of vehicles operating in the conditions of a large city. The proposed test tasks are focused on the use of stationary or laptop computers with the use of the game console driver (steering wheel, pedals, gear lever).

\section{MATERIALS AND METHODS}

Test tasks are imitation models of dangerous road and transport situations with an evaluation characteristic of the degree of development of sensorimotor qualities [4,5]. Figure 1 shows a schematic representation of one of the developed simulation test tasks for the hardware-software complex for diagnosing psychophysiological qualities of drivers of motor vehicles.

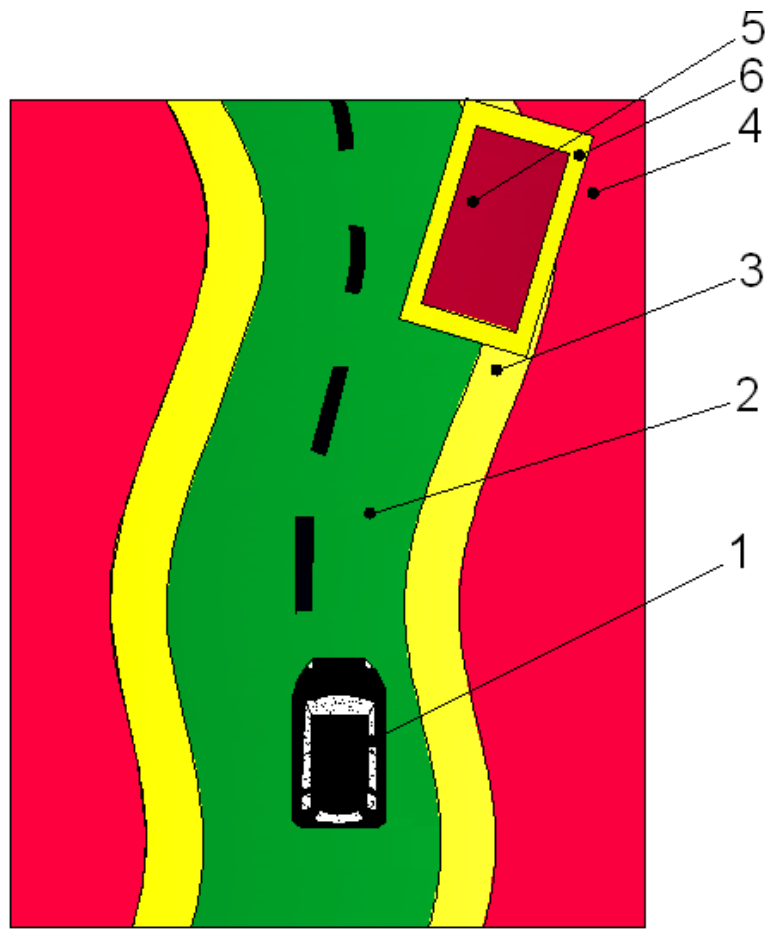

Fig. 1 Test "Driving on the road with fixed obstacles" 1 - "car" of the testing subject; 2- "road" contour (safety zone); 3 - the contour of the "roadside" (dangerous zone); 4 - contour of "near-road space" (critical zone); 5 - "parked 
car" contour (critical area); 6 - a contour of dangerous distance along the perimeter of a "parked car" (danger zone).

\section{RESULTS AND DISCUSSION}

When conducting research, especially in areas where precise single-valued deterministic estimation is difficult or impossible (for example, due to a large number of parameters, some of which are unknown or not explicitly taken into account), there arises the problem of convolution of results into a single, generalized criterion or several criteria for groups with reduction to the desired range.

The criteria obtained are then either used to perform computer analysis and information processing, or are provided to the person making the decision (DM) to justify the choice.

In developing the methodology for integrated support for the work of drivers of passenger vehicles and other operators of occupations, it was necessary to first obtain an assessment of the subject's passing through the test on a road simulator (in tests of different levels of complexity) and, second, to obtain a general criterion for passing standard and other known psycho-physiological tests.

To solve the first problem, the following convolution is proposed:

$$
R_{O D}=\frac{\left(\sum_{V_{\max }}\right)+d_{\mathrm{yo}}}{d_{\mathrm{o}}}
$$

where is the $\mathrm{R}_{\mathrm{OD}}$ - criterion of maneuvering, concerning dangerous zones of fixed obstacles;

$\mathrm{V}_{\mathrm{i}}$ - the speed at which the dangerous zone of the fixed obstacle intersects;

$\mathrm{V}_{\max }$ - maximum speed in the test task;

$\mathrm{d}_{\mathrm{y} 0}$ - number of successfully passed obstacles;

$\mathrm{d}_{0}$ - total number of dangerous obstacle zones.

Example: Total number of obstacles in test 15 , crossing hazardous areas 2, at speeds of 70 and $80 \mathrm{~km} / \mathrm{h}$, maximum test speed $90 \mathrm{~km} / \mathrm{h}$, then

$$
R_{O D}=\frac{\left(\frac{70}{90}+\frac{80}{90}\right)+13}{15}
$$

where is the $\mathrm{R}_{\mathrm{OK}}$ - criterion of maneuvering, concerning critical areas of fixed obstacles;

$\mathrm{V}_{\mathrm{i}}$ - the speed at which the critical area of the fixed obstacle intersects;

$\mathrm{V}_{\max }$ - maximum speed in the test task;

$\mathrm{d}_{\mathrm{yk}}$ - number of successfully passed obstacles;

$\mathrm{d}_{\mathrm{k}}$ - the total number of critical obstacle zones.

Example: The total number of obstacles in test 15, the intersection of critical zones 2, at speeds of 70 and $80 \mathrm{~km} /$ $\mathrm{h}$, the maximum test speed is $90 \mathrm{~km} / \mathrm{h}$, then

$$
R_{O K}=\frac{\left(\frac{70}{90}+\frac{80}{90}\right)+13}{15}
$$

$$
R_{R D}=1-\sum\left[\frac{\Delta t}{t}\left(1-\frac{V_{i}}{V_{\max }}\right)\right]
$$

where is the $\mathrm{R}_{\mathrm{RD}}$ - criterion of maneuvering, concerning dangerous road zones;

$\Delta \mathrm{t}$ - crossing time of the dangerous road zone at speed $\mathrm{V}_{\mathrm{i}}$, sec.;

$\mathrm{t}$ - the time of the test task, sec.;

$\mathrm{V}_{\mathrm{i}}$ - the speed at which the dangerous road zone intersects;

$\mathrm{V}_{\max }$ - maximum speed in the test task.

Example: The total test time is 300 seconds, the number of intersections of dangerous road zones 2, at speeds of 70 and $80 \mathrm{~km} / \mathrm{h}$, the duration of intersections is 2 and 5 seconds. accordingly, the maximum speed of the test is $90 \mathrm{~km} / \mathrm{h}$, then

$$
\begin{gathered}
R_{R D}=1-\left[\frac{2}{300}\left(1-\frac{70}{90}\right)\right]+\left[\frac{5}{300}\left(1-\frac{80}{90}\right)\right] \\
R_{R K}=1-\sum\left[\frac{\Delta t}{t}\left(1-\frac{V_{i}}{V_{\max }}\right)\right]
\end{gathered}
$$

where is the $R_{R K}$ - criterion of maneuvering, relative to critical road zones;

$\Delta \mathrm{t}$ - crossing time of the critical road zone at speed $\mathrm{V}_{\mathrm{i}}$, sec; $\mathrm{t}$ - the time of the test task, sec .;

$\mathrm{V}_{\mathrm{i}}$ - the speed at which the critical road zone intersects;

$\mathrm{V}_{\text {max }}$ - maximum speed in the test task.

Example: Total test time 300 seconds, the number of intersections of critical road zones 2 , at speeds of 70 and 85 $\mathrm{km} \mathrm{/} \mathrm{h}$, the duration of intersections 3 and 5 seconds. accordingly, the maximum speed of the test is $90 \mathrm{~km} / \mathrm{h}$, then

$$
\begin{gathered}
R_{R K}=1-\left[\frac{3}{300}\left(1-\frac{70}{90}\right)\right]+\left[\frac{5}{300}\left(1-\frac{85}{90}\right)\right] \\
R=\frac{a_{1} R_{O D}+a_{2} R_{O K}+a_{3} R_{R D}+a_{4} R_{R K}}{a_{1}+a_{2}+a_{3}+a_{4}}
\end{gathered}
$$

where the $\mathrm{R}$ - criterion of reliability of maneuvering, which is a generalized estimate of passing the test on the road simulator;

$a_{1}, a_{2}, a_{3}, a_{4}$ - additional coefficients of significance criteria for the resulting value $\left(a_{1}=0.2 ; a_{2}=0.8 ; a_{3}=0.2 ; a_{4}=0.8\right)$;

Drivers of vehicles participating in the studies also performed test tasks of the software complex "Effecton" [6]. In the work the modules of the program were applied: "Attention" and "Jaguar". These software applications are developed by the company for diagnostics of sensorimotor reactions and attention of specialists of various professions, for the effective labor activity of which the data of the PIQ group are needed.

The results of the test tasks of this psychological complex are interpreted on a 4-point system (5 - excellent, 4 - good, 3 - satisfactory, 2 - unsatisfactory).

When solving the second task, it is necessary to perform convolution in such a way that even a single "failure", 
inadmissible low parameter, greatly reduces the generalized criterion.

The following additive convolutions were considered:

the additive criterion in the form of the arithmetic mean

$$
Q=\frac{1}{3 n}\left(\sum_{i=1}^{n}\left(q_{i}-2\right)\right)
$$

The additive criterion in the form of a functional average

$$
Q=\frac{\sum_{i=1}^{n} \lg \left(3 q_{i}-5\right)}{n}
$$

The multiplicative criterion in the form

$$
Q=\prod_{i=1}^{n}\left(\frac{1}{3} q_{i}-\frac{2}{3}\right)
$$

The multiplicative functional criterion in the form

$$
Q=\prod_{i=1}^{n} \lg \left(3 q_{i}-5\right)
$$

The multiplicative functional criterion with extended interval of positive estimates

$$
Q=\frac{\prod_{i=1}^{n} \lg \left(33 q_{i}-65\right)}{2^{n}}
$$

where is the $\mathrm{n}$ - number of tests passed; $\mathrm{q}_{\mathrm{i}}$ - score in the test task.

The most sensitive is the criterion obtained by multiplicative convolution. In order to preserve sensitivity, but to avoid a large fall in the generalized criterion due to a small decrease in the quotients, the logarithm is taken from them. The obtained value is brought to the necessary interval by normalization using the best possible (ideal) values of the partial criteria.

Consider convolutions on the following sets of partial criteria based on the results of testing six subjects:

TABLE I. ADDITIVE CRITERION IN THE FORM OF THE ARITHMETIC MEAN (6)

\begin{tabular}{|r|r|r|r|r|r|r|r|r|r|r|}
\hline $\mathbf{q 1}$ & $\mathbf{q 2}$ & $\mathbf{q 3}$ & $\mathbf{q 4}$ & $\mathbf{q 5}$ & $\mathbf{q 6}$ & $\mathbf{q 7}$ & $\mathbf{q 8}$ & $\mathbf{q 9}$ & \multicolumn{1}{|c|}{$\mathbf{(}$} & \multicolumn{1}{|c|}{$\mathbf{Q}^{\mathbf{1}} \mathbf{( 2 , 5 )}$} \\
\hline 2 & 2 & 2 & 2 & 2 & 2 & 2 & 2 & 2 & 0 & 2 \\
\hline 2 & 2 & 2 & 2 & 3 & 3 & 3 & 3 & 4 & 0,222 & 2,666 \\
\hline 2 & 4 & 4 & 4 & 4 & 5 & 5 & 5 & 5 & 0,741 & 4,222 \\
\hline 3 & 3 & 3 & 4 & 4 & 4 & 5 & 5 & 5 & 0,667 & 4 \\
\hline 4 & 4 & 4 & 4 & 5 & 5 & 5 & 5 & 5 & 0,852 & 4,556 \\
\hline 5 & 5 & 5 & 5 & 5 & 5 & 5 & 5 & 5 & 1 & 5 \\
\hline
\end{tabular}

TABLE II. ADDITIVE CRITERION IN THE FORM OF THE FUNCTIONAL AVERAGE (7)

\begin{tabular}{|r|r|r|r|r|r|r|r|r|r|r|}
\hline $\mathbf{q 1}$ & $\mathbf{q 2}$ & $\mathbf{q 3}$ & $\mathbf{q 4}$ & $\mathbf{q 5}$ & $\mathbf{q 6}$ & $\mathbf{q 7}$ & $\mathbf{q 8}$ & $\mathbf{q 9}$ & $\mathbf{Q}$ & $\mathbf{Q}^{\mathbf{1}}$ \\
\hline 2 & 2 & 2 & 2 & 2 & 2 & 2 & 2 & 2 & 0 & 2 \\
\hline 2 & 2 & 2 & 2 & 3 & 3 & 3 & 3 & 4 & 0,361 & 3,084 \\
\hline 2 & 4 & 4 & 4 & 4 & 5 & 5 & 5 & 5 & 0,820 & 4,460 \\
\hline 3 & 3 & 3 & 4 & 4 & 4 & 5 & 5 & 5 & 0,816 & 4,447 \\
\hline 4 & 4 & 4 & 4 & 5 & 5 & 5 & 5 & 5 & 0,931 & 4,793 \\
\hline 5 & 5 & 5 & 5 & 5 & 5 & 5 & 5 & 5 & 1 & 5 \\
\hline
\end{tabular}

TABLE III. THE MULTIPLICATIVE CRITERION (8)

\begin{tabular}{|r|r|r|r|r|r|r|r|r|r|r|r|}
\hline $\mathbf{q 1}$ & $\mathbf{q 2}$ & $\mathbf{q 3}$ & $\mathbf{q 4}$ & $\mathbf{q 5}$ & $\mathbf{q 6}$ & $\mathbf{q 7}$ & $\mathbf{q 8}$ & $\mathbf{q 9}$ & \multicolumn{1}{|c|}{$\mathbf{Q}$} & \multicolumn{1}{|c|}{$\mathbf{Q}^{\mathbf{1}}$} \\
\hline 2 & 2 & 2 & 2 & 2 & 2 & 2 & 2 & 2 & 0 & 2 \\
\hline 2 & 2 & 2 & 2 & 3 & 3 & 3 & 3 & 4 & 0 & 2 \\
\hline 2 & 4 & 4 & 4 & 4 & 5 & 5 & 5 & 5 & 0 & 2 \\
\hline 3 & 3 & 3 & 4 & 4 & 4 & 5 & 5 & 5 & 0,011 & 2,033 \\
\hline 4 & 4 & 4 & 4 & 5 & 5 & 5 & 5 & 5 & 0,198 & 2,593 \\
\hline 5 & 5 & 5 & 5 & 5 & 5 & 5 & 5 & 5 & 1 & 5 \\
\hline
\end{tabular}

TABLE IV. THE MULTIPLICATIVE FUNCTIONAL CRITERION (9)

\begin{tabular}{|r|r|r|r|r|r|r|r|r|r|r|}
\hline $\mathbf{q 1}$ & $\mathbf{q 2}$ & $\mathbf{q 3}$ & $\mathbf{q 4}$ & $\mathbf{q 5}$ & $\mathbf{q 6}$ & $\mathbf{q 7}$ & $\mathbf{q 8}$ & $\mathbf{q 9}$ & \multicolumn{1}{|c|}{$\mathbf{Q}$} & \multicolumn{1}{|c|}{$\mathbf{Q}^{\mathbf{1}}$} \\
\hline 2 & 2 & 2 & 2 & 2 & 2 & 2 & 2 & 2 & 0 & 2 \\
\hline 2 & 2 & 2 & 2 & 3 & 3 & 3 & 3 & 4 & 0 & 2 \\
\hline 2 & 4 & 4 & 4 & 4 & 5 & 5 & 5 & 5 & 0 & 2 \\
\hline 3 & 3 & 3 & 4 & 4 & 4 & 5 & 5 & 5 & 0,132 & 2,395 \\
\hline 4 & 4 & 4 & 4 & 5 & 5 & 5 & 5 & 5 & 0,510 & 3,530 \\
\hline 5 & 5 & 5 & 5 & 5 & 5 & 5 & 5 & 5 & 1 & 5 \\
\hline
\end{tabular}

TABLE V. MULTIPLICATIVE FUNCTIONAL CRITERION WITH EXTENDED INTERNAL OF POSITIVE ESTIMATES (10)

\begin{tabular}{|r|r|r|r|r|r|r|r|r|r|r|r|}
\hline $\mathbf{q 1}$ & $\mathbf{q 2}$ & $\mathbf{q 3}$ & $\mathbf{q 4}$ & $\mathbf{q 5}$ & $\mathbf{q 6}$ & $\mathbf{q 7}$ & $\mathbf{q 8}$ & $\mathbf{q 9}$ & $\mathbf{Q}$ & $\mathbf{Q}^{\mathbf{1}}$ \\
\hline 2 & 2 & 2 & 2 & 2 & 2 & 2 & 2 & 2 & 0 & 2 \\
\hline 2 & 2 & 2 & 2 & 3 & 3 & 3 & 3 & 4 & 0 & 2 \\
\hline 2 & 4 & 4 & 4 & 4 & 5 & 5 & 5 & 5 & 0 & 2 \\
\hline 3 & 3 & 3 & 4 & 4 & 4 & 5 & 5 & 5 & 0,342 & 3,025 \\
\hline 4 & 4 & 4 & 4 & 5 & 5 & 5 & 5 & 5 & 0,695 & 4,085 \\
\hline 5 & 5 & 5 & 5 & 5 & 5 & 5 & 5 & 5 & 1 & 5 \\
\hline
\end{tabular}

where is the $\mathrm{q}_{\mathrm{i}}$ - evaluation in the test task;

$\mathrm{Q}$ - is a multiplicative criterion for evaluating the results of performing psychological tests «Effecton» within the range from 0 to 1 ;

$\mathrm{Q}^{1}$ - is a multiplicative criterion for evaluating the results of performing psychological tests "Effecton" within the values from 2 to 5 .

\section{CONCLUSIONS}

As can be seen from the comparison of the results, the most successful and obvious is convolution (10).

Comparing the general criterion and the maneuvering factor $\mathrm{R}$, we establish the full or group (selective) equivalence of the results obtained on the simulator and the results of the psychological tests.

\section{REFERENCES}

[1] N.Sadovnikova, D.Parygin, M.Kalinkina, B. Sanzhapov, and Trieu Ni $\mathrm{Ni}$, "Models and methods for the urban transit system research", CIT\&DS 2015 : Proceedings of the First International Conference on Creativity in Intelligent Technologies \& Data Science, Volgograd, Russia, 15-17 September 2015. - Springer IPS,. - CCIS 535. 2015, pp. 488-499.

[2] Yu.Ya.Komarov, R.A.Kudrin, E.V.Lifanova, and M.N.Dyatlov, "Definition of professionally important qualities of the drivers necessary for efficient control by passenger motor transport", The Science and the technics of transport. 2016, № 2, pp.14-18.

[3] Yu.Ya.Komarov, R.A.Kudrin, E.V.Lifanova, A.N.Todorev, and M.N.Dyatlov, "Expert estimations of professionally important qualities of drivers of passenger motor transport", The Motor transportation enterprise. 2016, № 5, pp.10-13.

[4] M.N.Dyatlov, O.A.Shabalina, Yu.Ya.Komarov, and R.A.Kudrin, "Development of test tasks for computer diagnostics of the development degree of sensorimotor reactions taking into account the peculiarities of professional activity of drivers", News of VSTU. Actual problems of 
management, computer facilities and computer science in technical systems. - Volgograd, 2016, № 6 (185), pp. 33-39.

[5] M.N.Dyatlov, A.R.Agazadyan, and O.A.Shabalina, "The Hardwaresoftware complex for testing of professional qualities of drivers of passenger motor transport at a stage of professional selection", The Bulletin of computer and information technologies. 2016, № 12 (150). pp.48-55.

[6] Complex of tests Effecton Studio [the Electronic resource] URL: http://www.effecton.ru/03.html (reference date: 02.09.2017) 